\title{
MECHANISMS OF MANAGEMENT OF DEVELOPMENT OF REGIONAL AGRO- INDUSTRIAL COMPLEXES ON BASIS OF PROGRAM-TARGET APPROACH
}

\author{
Vasilii Trenev, Tatiana Treneva \\ Moscow State University of Education, Russia \\ vttrenev@gmail.com, ladymirta@yandex.ru
}

\begin{abstract}
The paper suggests the principles of implementing mechanisms to manage the development of large regional agricultural complexes based on a program-targeted approach. The following topics are discussed: problems and requirements of the regional development management system; methodical approach and main elements of the system; principles of management, goal-setting mechanisms and required management outcomes; an example of requirements for the end result statement; procedure to develop and manage the implementation of the development program of regional agricultural complexes; organizational structure of the development management system; principles of authority and responsibility distribution. The present paper discusses the problems associated with the formation of the result-oriented organizational structure of management and staffing problems of the regional development processes.
\end{abstract}

Keywords: development, development management, development management system, goal-setting, sales management, result-oriented organizational structure.

\section{Introduction}

\section{Disadvantages in the regional development management system}

The state of the development management system in most regions often leaves much to be desired.

First of all, the overwhelming majority of agrarian regional entities lack development management as a system - or there are no such units, or/and there is no effective mechanism complex for development management.

Second, real management of obtaining implementation results of regional targeted programs, targeted investment programs and development projects throughout the year has a number of significant shortcomings:

- in the middle of the year the regional administration analyses actual data, as a rule, only on the "absorption" of budget funds;

- the full yearly report is drawn and analysed not earlier than in the first quarter of the next year.

Accordingly, the "plan-fact" analysis and control actions can no longer be used to either improve the annual results, or take them into account when approving the programs, plans and budgets of the next year, which are approved in November-December. The management feedback is lost and the process of development turns out to be almost uncontrollable according to yearly results.

\section{Desirable properties of the regional development management system}

A regional development management system should preferably include organizational mechanisms that allow:

- generalizing the practical experience of successful (by results) application of program-target management and a number of other modern effective management methods;

- provision of a comprehensive ("turnkey") solution to the problem of significantly improving development efficiency and the efficiency of using budgetary funds.

First of all, the development management mechanisms should help receive answers to the following questions.

1. "Which results do we want to obtain?" (methods to form a multi-level system of final and intermediate goals and criteria at various organizational levels of the management object territorial agro-industrial complex).

2. "What leads to the desired results?" (methods to assess the potential of achieving goals, methods to select priority areas, targeted programs and development projects, which mainly contribute in improving the final results). 
3. "How to manage development?" (development management mechanisms - a set of regulations, business processes, information technology).

4. "Who will manage the development of which units?" (organizational structure of development management, functions of units, distribution of responsibility and authority).

\section{Materials and methods}

The main methodological tool that can provide a comprehensive solution to the problem of improving the efficiency of development and using budget funds is a program-targeted approach to management.

\section{The main elements and functions of the regional development management system}

The basis of an effective development management system [1;2] is a complex organizational mechanism system, application of which can ensure the achievement of high final socio-economic results and a significant improvement in efficient use of financial resources.

The program for the development of a regional industrial and agricultural complex consists of three main parts (subprograms):

1. development of the social sphere, which allows to attract and retain qualified personnel on a permanent basis (social development program);

2. development of the real economic sector (economic development program);

3. other changes (infrastructure, management systems, mechanisms of external interactions, etc.).

Within the framework of these subprograms, in accordance with the principles of the programtarget approach, it is necessary to perform the following work stages:

1. refinement of the concept result (definition of the criteria characterizing the degree of goal achievement and statement of the objectives, that is, the desired values of these criteria);

2. building a model to assess the consequences of the decisions made and identify the main factors (success factors) and indicators, the changes that most strongly affect the final result;

3. determination of influence methods (measures) that ensure the necessary change in essential factors;

4. development of a system to record and monitor the actual value of these factors and indicators;

5. allocation of development queues and implementation of management system results, including a program of changes;

6. technology implementation of the first phase of changes (including workflow);

7. preparation and implementation of the following activity queues.

The development management system, just as any management system, includes the following main elements.

1. Mechanisms (regulations and procedures) of management, including:

- program and target management and project management;

- results-based budgeting (RBB);

- motivation of participants for final results, etc.

2. Participants of the development and implementation of development programs, including:

- head administration of the regional agricultural complex;

- management of targeted programs;

- development infrastructure.

3. Unit (organizational structure), the purpose of which is the management of development of the administrative business in the regional agricultural complex and the main functions, including:

- formation of agreed goals, sub-targets and key indicators characterizing the results of operations;

- preparation of decision-making on allocation and sequestration of development budget funds;

- development of regional standards, development management regulations and monitoring of implementation;

- coordination of work on programs and projects, priority at the regional level (and giving the main contribution to the growth of target indicators); 
- system of responsibility, authority and motivation in the sphere of development;

- targeted retraining of managers and all participants in the development and implementation of development programs.

\section{Planning procedures}

The planning procedure includes:

- operational planning and control of actual results;

- yearly (quarterly) planning development;

- medium-term development planning (for 3 years on year);

- long-term forecasting and justification for 12 years, including the development of the forecast, concepts and strategies for the development of the region).

The receipt of immediate real end results occurs at the operational management stage through the implementation of works and development projects included in the plan. Selection and approval of the work program of the development program, i.e. a set (package) of projects and budget occurs during the development of an annual comprehensive development plan.

The analysis of the widest possible field of potential fields and projects, justification and allocation of priority (giving the main contribution to the results) is carried out at the stage of mediumterm planning. At this stage, the priority areas are identified, which are worked out in the form of targeted programs and priority projects for changes (innovations).

A deeper rationale can be made with long-term planning (forecasting, development strategy development).

Unlike prospective programs, the medium-term program and the development budget (for example, three-year programs) should be mandatory by first planning documents approved at all levels, including the federal level.

The first documents to be approved at all levels and which play the role of the task plan for the implementation of specific works and results, are the annual plan and the development budget. The program and budget for the following years play mainly the role of justification for making a decision to include reserve projects that give results in subsequent years to the first-year program.

The main task is a significant increase in the efficiency of budgetary fund use (management at all stages and levels of the final financial result) - the achievement of the set social goals at the minimum cost. And for some of the tasks of economic development - obtaining the maximum financial and economic result (value added, gross regional product, budget revenues, etc.).

The ultimate goal is to improve the well-being of the population (level and quality of life), measured by the achieved values of several dozen social indicators (per capita income, mortality rate, level of education, housing, medical services, etc.). This requires financial resources, the main source of which is the expenditure part of the budget of the territorial federation subject and municipalities.

At the same time, the main source that covers the revenue side of the budget and average wage growth is the real sector of the economy, including the agro-industrial complex, transport and communications, trade and paid services, construction.

\section{Management principles}

According to Ackoff R. and Emery F. [3] all organizations are purposeful by their nature, as they are created to achieve certain goals.

When managing such systems, it is reasonable to use program-target management methods.

The main categories of program-target management (PTM) are the ultimate goal of development and the means to achieve it (programs, projects, resources, organizations, etc.).

The main principle of the PTM is unconditional submission of all available means to the practical achievement of ultimate goals (obtaining actual results).

The main task of the PTM is to maximize the efficiency (effectiveness) of using scarce resources:

- with limited resources and fixed terms, to maximize the extent of achievement of the end result;

- with predetermined goals (targets) to ensure their achievement with minimal costs. 
The main tool for solving this problem is a set of results-oriented budgeting methods.

The most important in the process of program-target management is the integrated management of the target (for results) according to the plan: "goal - sub-goals - tasks - work program planning (with grounding to specific projects and enterprises) - providing them with resources - implementing the program - obtaining final results (achievement of goals)".

The basic principles of results management for any single-purpose organization (regional or territorial administration, specific firm) include:

1. planning from the final goals (desired results) to the means, up to the program of specific works, to the divisions and personal executors;

2. monitoring of the actual performance and evaluation of the performance of units, implementing projects and works on the criteria that characterize the degree of achievement of goals;

3. assessment and selection of decisions to manage impacts (changes) at all levels (works, projects, divisions and the firm as a whole) on the basis of forecasting the impact of these changes on the final result;

4. allocation of scarce resources, first of all, to priority, more profitable activities for final result;

5. motivation for the departments and personnel to improve the final results;

6. development and implementation of policies and mechanisms ("rules of the game", business processes) that ensure maximum implementation of the existing potential of the organization to achieve the ultimate goals.

These principles of targeted management should be implemented when developing, approving, adopting and executing management decisions:

- at all management levels;

- for all periods - long-term (6 years and more), medium-term (2-3 years), yearly (yearquarter), prompt (month-week) plans;

- at all cycle stages of the business projects and development projects.

To ensure maximum results (the final result), it is necessary to ensure the possible completeness (complexity, systematicity) of factors, relationships and constraints considered that significantly influence on decision-making and ensure achievement of the goal. Based on the results of analysis and allocation of the most significant indicators in the region, municipalities, enterprises and corporations, it is necessary to organize a system of management report and control of these indicators.

The most important are indicators of the effectiveness of the use of available resources, primarily financial (return on the rouble costs, output per worker, etc.), which are continuously growing and determine the competitiveness in the world.

\section{Goal-setting}

The key stage in development management procedures is the goal-setting stage.

In the process of goal-setting, regional objectives (including the higher level), objectives and priorities should be taken into account.

The system of goals for the development of the real economic sector (for example, the agroindustrial sector) should be formed "from the top down" in the structure "head administration administration of structural units".

The system of social development goals should begin "from the bottom up," from administrations of specific sites and units that are "closer to the people", which better represent the real situation, problems and required changes that take into account the specific nature of the specific territory.

When building a tree of goals at each level, each sub goal should contribute to the achievement of the goal and the achievement of the whole set of sub goals should ensure the achievement of the goal of a higher level.

When constructing a criteria tree, each criterion should contribute to a higher criterion, be measurable (controllable) or computable, and the set of lower-level criteria and the algorithm for their convolution should be sufficient to determine the value of the higher criterion.

As a result of the work on the formation of the system of goals, a document "System of development goals and development criteria" is created: 
- general statement of development goals;

- development goal tree ("goal-means");

- criteria tree;

- target settings for 3 years and forecast for 6 years as a whole;

- sets of criteria (key indicators) characterizing the performance of the administration units, their contribution to the achievement of the ultimate goals;

- target setting for 3 years and a forecast for 6 years for departments and committees of the administration;

- for regional priorities, federal target programs implemented in the region (regional and departmental target programs, targeted investment program);

- for municipal restrictions.

Target settings should be realizable, i.e. coordinated with the set of specific work programs, with the availability of financial and scarce labour resources.

A reporting system that allows real-time control of efficiency should include:

- monthly monitoring of actually achieved results by target settings of all levels with automatic reporting of achieved criteria values and cumulative costs, always available for verification;

- quarterly submission of interim summary reports to higher-level organizations on the implementation of priorities (for priority projects);

- half-year report in the form of a "fact-plan" is provided to the region's head in June (the required management actions are built on its basis, including the involvement and redistribution of resources, activating or deactivating certain targeted programs, etc.) according to the approved criteria (primarily including actual costs and proposals for the correction of work programs, development budgets and, possibly, target settings);

- final report on the development results for the year for the whole set of criteria is formed in two stages: a short forecast late in November (it is used to clarify the next year's development program) and the final full one at the end of January.

The structure of internal reporting and management reporting policies should be defined in the process of developing the management system for a particular region.

\section{Coordination of the development of programs in the social and the real economic sectors}

The social sphere and the real economic sector differ significantly as management objects. Their development programs are developed and managed by different executors. However, they have significant interrelationships:

- through the budget (implementation of the development program of the real sector provides an increase in the revenue side of the budget, which is the main restriction for the implementation of the social sector development program);

- salary and purchasing power of the population;

- restrictions on manpower (human capital) used in both programs;

- etc.

In the recommended procedure for the development of the Program, it is proposed to perform the most labour-intensive studies of social and economic programs in parallel (with a single methodological basis of program-target management), with the subsequent linking of the parts into a single program according to the following plan.

1. In the social sphere:

- The values of the criteria corresponding to the estimates of the degree to which the social goals are achieved are set as "excellent", "good", "satisfactory";

- At the first iteration, the requirements for the growth of the revenue part of the budget, which is necessary to ensure achievement of social goals "excellent", are appreciated, and these requirements become targeted for the real economic sector;

- At the final iterations, projects that can provide the required increment in results are identified and costs are estimated for them (by years); 
- The total costs and requirements for the growth of the expenditure part of the budget in the future and for the growth of the purchasing power of the population (per capita income) are determined.

2. The innovative development potential of the real economic sector and the maximum possible rates of economic growth, the maximum possible growth of the gross product, the revenue side of the budget and the salary are estimated at the same time.

3. A comparison is made between the required increase in the expenditure side of the budget and the technologically maximum possible increase in the revenue side. If the growth of the revenue part is sufficient, then the achievement of the goal with an "excellent" level is possible and this development scenario can be detailed further.

If it is not enough, then with the BOR methods, the budget funds are redistributed (sequestered) under social development projects, the deadlines for achieving the "excellent" goal are adjusted and the degree of its achievement is specified at the end of the period.

4. The obtained version is concretized before the work program, financing sources and possibilities to obtain it.

5. In addition to the received optimistic option, an inertial option of the economic program and its working option are formed (with real attracted investments).

6. The working version of the social program and the Program as a whole are formed and then approved under the working version of the economic program.

7. The management system for the working version (scenario) of the program is developed and approved.

\section{Organizational structure of the development management system}

The organizational structure (unit composition, their functions and subordination) should be chosen in such a way as to best implement the set of mechanisms (regulations) of the program-target management.

The most effective in the development management system for results is the matrix (synonyms program-target, project) organizational structure.

The main element of the matrix organizational structure that provides about $80-85 \%$ of the contribution to the achievement of ultimate goals (this is the main feature that distinguishes it from the existing one) is a set of priority directives (target programs, priority projects of changes, innovations, venture projects, etc.). Each target program is comprehensive, holistic and includes (under a single leader) everything that is necessary to achieve the final results:

- clearly formulated final and intermediate results;

- full range of works;

- full control cycle;

- project team that has mastered the mechanisms of the PTM and project management for results;

- project budget;

- etc.

The goals and goal setting for targeted programs and priority project changes, including the "assembling" of their particular results into a single final development result, as well as the management of the consolidated development budget, is carried out by the consolidated body (for example, the Centre of program-target management) under a general manager or with his deputy, responsible for the development results, the efficiency of multi-project management and use of budget funds (development budget).

Functional departments are co-executors (subcontractors) of all complex programs in the sphere of their competence.

The branch departments have two main functions:

- on the one hand, they also act as co-executors of the sectorial sections of the part of the CP; 
- on the other hand, they can be consumers of some of the results and sometimes customers (especially - on departmental CP).

The creation of a fully functioning matrix organizational structure to manage the development of a large regional agro-industrial complex is required from one to two years. This is due to the time spent on its detailed design (up to the staff schedules and job descriptions). It is required to change the mentality and target reformation of a significant part of personnel, to overcome the resistance to change (especially - the responsibility for real results and additional control of targeted and effective use of budget funds), changes in a number of federal and regional legislative and regulatory acts.

\section{Responsibilities and power distribution principles}

When allocating responsibilities and authority in the regional development management system, the following basic principles should be observed.

- The responsibilities for obtaining partial (or intermediate) results should be distributed among the responsible executors so as to fully ensure the achievement of the final goals.

- The responsibilities for the results of the targeted programs and the development Program as a whole should be provided with sufficient powers to make decisions about the management impacts and to dispose of the necessary human and financial resources.

- The process of setting goals and their achievement should be described in the mechanism (regulations) forms under a single standard.

- All stages and mechanisms (regulations) documents for the development management and implementation of the Development Program should be assigned to a specific subdivision and individual executor.

- All functions (solved tasks) of each division of the development management system should be set only from blocks (tasks) included in the regulations and contribute to obtaining final or intermediate results.

\section{Some problems of staffing of regional development processes}

To manage the development processes in the existing organizational management structure, a separate unit appears, which initiates the change processes and manages their implementation [2-4]. Its functions include setting goals and targets (for targeted programs and priority projects of changes), coordinating and "assembling" private results into a single final development result. It can be a consolidated body (for example, the centre of program-target management [4]) under a general manager or the first deputy responsible for development results appointed by him, for the efficiency of multi-project management and for using the development budget. The members of this division are united by one feature - they are internally oriented towards innovative changes. This is in fact a unit consisting of entrepreneurs.

There is an inexorable shift in the world from the "managerial" economy to "entrepreneurial" economy.

Innovation is a special tool of entrepreneurs, a means by which they use innovations as an opportunity to realize their intentions. The task of the entrepreneurs includes a targeted search for sources of innovation. And according to Schumpeter [5], the "norm" of a healthy economy is not equilibrium, but dynamic disequilibrium caused by the activity of innovator-entrepreneurs, who seek changes, react to them and use them as a source of success.

For the units that initiate the changes, the organizational structure described by G. Morgan [6] with the metaphor "organization as a holographic brain" is most suitable. It is a system, in which the properties of the whole are contained in each of its parts, as a result of which the system acquires the capacity for continuous self-organization. The basis is the approach to organization as an information and communication system, like the brain constantly processing information, generating knowledge, developing and making decisions based on this knowledge. This approach is based on the theory of decision-making, as well as the concept of N. Winner [7] on the processes of self-regulation of complex systems based on information exchange. Self-regulation begins when a constant information exchange is established between the object and its external environment, allowing it to notice the changes taking place in time and generate corresponding reactions to them. Such a system is capable of reconsidering the norms and rules that serve as the basis for its self-regulation, not just adapting to 
the environment, but, constantly analysing this environment, seeking to develop a new point of view on it, changing its view on the social, cultural and other context of its activities, actively seeking new opportunities for development.

Based on the above, we can formulate the following principles for the development of the organization.

1. "The whole in each of its parts".

Understanding of values, tasks, ideas, the central idea and other dimensions of the corporate culture must be learned, "absorbed" by each employee. Then he has the opportunity to act, with a notion of the whole.

2. "Network mind".

It is necessary to develop information systems, accessible by each employee from various points. Open information exchange allows any employee to be an active participant in developing events.

3. "Holographic structure".

A company that is too large makes communication between employees difficult. Therefore, if there is a need to grow the organization, it is more desirable to open new branches than continue to increase the number of employees within one enterprise.

4. "Team integrity and role variety".

The team is responsible for the overall process and results of operations. There is no hard division of roles, employees have many skills and abilities, they can replace each other.

A self-learning organization makes high demands on individual abilities, professional training of the employee. There is a need for motivation for hard and complex work and readiness to perform a wide range of duties. In fact, this is a requirement for non-situational behaviour from the employee. The more deep and positive the idea of innovation in the mind of an employee, the more valuable and meaningful it is for him, the more amount of effort he will be ready to apply for its implementation. Thus, we believe that in order to select personnel for the target team, it is necessary to diagnose the potential employee's positive attitude toward changes and the absence of fear of change.

It is important for the employee to receive objective and timely information about the results that the target team brings. And if positive information prevails, we can talk about increasing the likelihood of occurrence of a non-situational behaviour.

It is important for the employee to form an idea of the target team as a group of like-minded people united by one common idea and leading their activities in the interests of all their members. This factor also increases the likelihood of occurrence of non-situational behaviour.

\section{Requirements to the final results of management}

The structure of the requirements for the final and intermediate development results for the regional agricultural complex in general and for each subdivision in a particular territory includes [1]:

- brief description, vision of the regional complex image (territorial unit) at the end of the planning horizon;

- general statement of development goals, highlighting the most important, strategically important results (and criteria) for this planning period (at the end of the third year) for this regional complex (territorial unit);

- target settings to change the criteria value by year for the accepted planning horizon (for example, for the first 3 years and their forecast for the next three years);

- target settings for a complete list of reporting criteria;

- target setting for a set of 15-20 management criteria, the most significant for obtaining the main results for this particular regional complex (territorial unit).

In addition, the system of goals and criteria includes targets for part of the outcome criteria and indicators of intermediate results that characterize the performance of each of the key performers in their contribution to the achievement of the ultimate goals. 


\section{Conclusions}

Currently, in the post crisis period, with fairly low rates of development, most of the regional agro-industrial complexes are in a difficult state. To ensure a quick way out of this situation under conditions of reduced financial resources, it is necessary to use adequate and more stringent, productive and effective methods of management.

Such methods are known and repeatedly used in the country in situations, where it was required to obtain strategically important results for the country (region, corporation) in a short time. These are the methods of program-target management that are the concretization of the system approach to development management oriented towards obtaining real end results throughout the whole management process.

\section{References}

[1] Irikov V.A., Novikov D.A., Trenev V.N., Integrative system of public and private management of innovative development as a means of doubling the pace of Russia's exit from the crisis and postcrisis growth. - M: IHP RAS, 2009. (In Russian).

[2] Ириков В.А. Активное инновационное антикризисное управление: успешный опыт и рекомендации по его использованию. (Active innovative crisis management: successful experience and recommendations for its use) - Moscow: "Moscow Institute of Energy Security and Energy Conservation”, 2009 г, 84стр.(In Russian)

[3] Ackoff R.I., Emery F. E. On Purposeful Systems. Chicago: Aldine- Atherton, 1972.

[4] Leontiev S.V., Masyutin S.A., Trenev V.N. "Strategies of success: a generalized experience of reformation of Russian industrial companies". Novosti Printing House, 2000. (In Russian).

[5] Schumpeter J. The theory of economic development. Capitalism, Socialism and Democracy / Preface V.S. Avtonomova. - M .: EKSMO, 2007. - p. 864 - (Anthology of economic thought). (In Russian)

[6] Morgan G. Image organization: eight models of organizational development. - M .: Vershina, 2006. (In Russian)

[7] Wiener N. Cybernetics or Control and Communication in Animal and Machine. / Transl. from Eng. I.V. Solovyov and G.N. Povarova; Ed. G.N. Povarova. - 2nd edition. - Moscow: Science; Main edition for foreign countries, 1983. (In Russian). 